\title{
A SERO-EPIDEMIOLOGICAL STUDY OF HERPES SIMPLEX VIRUS- 2 ANTIBODIES AMONG PATIENTS WITH SEXUALLY TRANSMITTED INFECTIONS
}

\author{
Kavitha K', K. Abdul Samad ${ }^{2}$
}

1 Junior Resident, Department of Dermatology \& Venereology, Government Medical College, Trivandrum, Kerala, India.

${ }^{2}$ Additional Professor, Department of Dermatology \& Venereology, Government Medical College, Trivandrum, Kerala, India.

ABSTRACT
BACKGROUND
Herpes genitalis (HG) is a sexually transmitted infection of great public health importance. HSV-2 is the major cause of the infection
in more than $80 \%$ of such cases. Many patients with other sexually transmitted infections (STIs) without clinical signs and
symptoms of HG also were found to have serological positivity for HSV-2 on serological screening for STIs.
Objective- To study the seroprevalence of HSV-2 antibodies in patients with HG, 'Other STIs' and a cross section of the general
population in the STI clinic attached to the Department of Dermatology and Venereology of Medical College, Thiruvananthapuram,
one of the biggest tertiary care centre in South India.

\section{MATERIALS AND METHODS}

51 patients who attended the clinic with various STIs and an equal number of individuals of the sexually active age group as a comparison group were screened for HSV-2 IgM and IgG antibodies tested by ELISA and the titres were recorded. Statistical analysis was done by an appropriate computer software and Chi-square test as a non-parametric test.

\section{RESULTS}

HSV-2 IgM or IgG was positive in $58.8 \%$ of STI patients, $95.2 \%$ of HG cases, $33.33 \%$ of patients with 'other STIs' and $27.45 \%$ of individuals of the comparison group representing the general population.

\section{CONCLUSION}

The HSV-2 seropositivity rates in patients with 'other STIs' (33.3\%) and in the general population (27.5\%) who in fact are patients with asymptomatic genital herpes infection, strongly indicates the necessity for screening all STI patients and vulnerable individuals of the general population to serologically screen for genital herpes infection.

\section{KEYWORDS}

Herpes Genitalis, Seroprevalence of HSV-2 Antibodies.

HOW TO CITE THIS ARTICLE: Kavitha K, Samad KA. A sero-epidemiological study of herpes simplex virus-2 antibodies among patients with sexually transmitted infections. J. Evolution Med. Dent. Sci. 2017;6(49):3738-3741, DOI: 10.14260/Jemds/2017/808

\section{BACKGROUND}

Herpes genitalis is primarily a disease of young adults, caused by two serotypes of herpes simplex virus (HSV), 1 and $2 .{ }^{1}$ It is a disease of major public health importance. HSV-2 is the major cause of genital herpes virus infection occurring in 80$90 \%$ of cases. The disease can present either as a primary infection or recurrence exhibiting a variety of clinical features. Accurate evaluation of seroprevalence of HSV-1 and HSV-2 has been markedly enhanced by the development of type specific serological assays which have sensitivity and specificity better than culture. Such assays use purified type specific proteins such as glycoproteins gG1 and gG2 which are antigenically distinct between two subsets. ${ }^{2}$ Studies of serological prevalence of HSV-2 infection among STI patients and general population are lacking in most of the STI clinics in the country.

Financial or Other, Competing Interest: None.

Submission 29-05-2017, Peer Review 09-06-2017,

Acceptance 12-06-2017, Published 19-06-2017.

Corresponding Author:

Dr. Abdul Samad K,

Additional Professor,

Department of Dermatology and Venereology,

Government Medical College,

Trivandrum-695011,

Kerala, India

E-mail: drsamad_1961@yahoo.co.in

DOI: $10.14260 /$ jemds $/ 2017 / 808$

(c) (i) $\$$
Incidentally, many patients with STIs other than herpes genitalis were observed to have significantly high titres of HSV-2 IgM or IgG antibodies.

Hence, we designed this Study with the following Aims-

1. To study the seroprevalence of HSV-2 antibodies among all patients with STIs.

2. To know whether there is any difference in serological titre between herpes genitalis patients, patients with other STIs and general population.

3. To derive the prevalence of asymptomatic HSV-2 infection among patients with other STIs and general population.

\section{MATERIALS AND METHODS}

This study was a descriptive study undertaken in the Department of Dermatology and Venereology of Medical College, Thiruvananthapuram, South India for a period of one year. 51 patients who attended the STI clinic and showed evidence of at least one STI were subjected to serological screening for HSV-2 infection. 51 people belonging to the sexually active age group devoid of evidence for any type of sexually transmitted infections and who gave consent for the study were included as a comparison group. After taking a detailed history using a standard proforma, a clinical examination of the study group patients was done and the findings were recorded. 
Serological test for HSV-2 IgM and IgG antibodies were done with the help of separate HSV-2 serological titre analysis kit using Enzyme Linked Immuno Sorbent Assay (ELISA) technique and the titres were recorded. Other relevant blood investigations significant for each case were also undertaken. The test kit used included antihuman IgG/IgM horseradish peroxidase conjugate with appropriate reagent solution, dilution and wash buffers and substrate solution along with negative control, cut-off control and positive control serum samples. The serum samples from the study group patients were collected during their second visit in the clinic to avoid false negativity during the earlier phase of infection. ELISA for IgG and IgM antibodies were done separately for all samples. The titre was calculated using the standard formula of Mean Absorbance Value multiplied with 10 and divided by the cut-off value. A ratio of more than 1.1 is taken as a positive result, less than 0.9 is taken as a negative result and between 0.9 and 1.1 is taken as equivocal. Statistical analysis was done using the computer software, Statistical Package for Social Sciences (SPSS), $10^{\text {th }}$ version. The data were expressed in frequencies and percentages to elucidate the association and comparison between different parameters. Chi-square test was used as a nonparametric test. For all statistical evaluation, a two-tailed distribution was assumed and a probability value less than $0.05(\mathrm{p}<0.05)$ was considered significant.

\section{RESULTS}

Out of the 51 STI patients studied, 21 patients were diagnosed as genital herpes and the rest 30 patients had 'other STIs' which consisted of 14 cases of latent syphilis, of unknown duration, 9 cases of condylomata acuminata, 1 case of chancroid and 2 cases of mixed STIs. The 51 subjects of the comparison group did not show evidence of any of the STIs. Majority of the patients in the study group belonged to 31-40 years age group (35.3\%) and the mean age was 33.65 years. 21 patients were male $(41.2 \%)$ and 30 were female $(58.8 \%)$. Male to female ratio was 0.7:1. 21 patients were home makers $(41.2 \%)$ and 14 patients were manual labourers (27.5\%). 40 patients $(78.4 \%)$ were married and $8(15.7 \%)$ were unmarried.

All the 21 patients diagnosed as herpes genitalis (HG) presented with vesicles or erosions over the genitalia and 3 of them (14.3\%) had associated dysuria. 5 patients were diagnosed as Primary HG and 16 were diagnosed as Recurrent HG. All the patients with Primary HG and 13 patients with Recurrent HG presented with prodromal symptoms and pruritus was the commonest symptom. Fever and headache were the other associated symptoms. Tingling sensation, pain and fever were noticed by 1 patient each from both groups of HG patients. The incubation period ranged from 1-5 days in 12 patients with HG (57.1\%) and 6-10 days in 6 patients $(28.6 \%)$ with HG. The precipitating factors for triggering recurrence in HG patients were trauma during intercourse, physical strain and menstruation. 19 patients out of the total 51 patients (37.3\%) had marital sexual contact and 14 patients (27.5\%) had extramarital contact whereas 3 patients out of 21 with herpes genitalis (14.3\%) had marital contact and 8 patients (38.1\%) had extramarital contact, clearly indicating that extramarital contact was associated with transmission of herpes genitalis when compared with all other STIs.

Regional lymphadenopathy was more commonly found with recurrent HG (8 patients) than primary (2 patients) indicating that lymphadenopathy occurs with increasing duration of the disease. Extragenital lesions were present in 5 patients $(23.8 \%)$ of herpes genitalis, all patients being male and thighs were the sites affected.

Tzanck smear examination in patients with HG was positive for multinucleated giant cells in 4 patients (19\%) of which 1 was a recurrent HG case and the remaining 3 were recurrent HG cases. VDRL and TPHA reactivity were observed in all the 14 syphilis cases and none of the other STI patients.

Out of the 51 cases of all STI patients, HSV-2 serology, either IgM or IgG were positive in 30 cases (58.8\%). It was positive in 20 out of the 21 patients with HG (95.2\%), 10 cases out of the 30 patients with other STIs (33.33\%) and 14 of the comparison group of 51 subjects (27.45\%). Among the 21 HG cases, HSV-2 IgM was positive in 12 cases (57.1\%) which included 3 out of the 5 primary HG cases (60\%) and 9 out of the 16 recurrent HG cases $(56.25 \%)$. HSV-2 IgM was positive in 2 cases of other STI cases $(6.67 \%)$ including 1 case of latent syphilis of unknown duration and 1 case of condylomata acuminata and in 3 subjects of the comparison group (5.9\%). Equivocal values of IgM titres were observed in 1 patient of the other STI cases and 2 subjects of the comparison group. (Table-1).

\begin{tabular}{|c|c|c|c|}
\hline HSV-2 IgM & $\begin{array}{c}\text { Herpes } \\
\text { Genitalis } \\
\text { (Total No. } \\
\text { 21) }\end{array}$ & $\begin{array}{c}\text { Other STIs } \\
\text { (Total No. } \\
\mathbf{3 0 )}\end{array}$ & $\begin{array}{c}\text { Comparison } \\
\text { Group (General } \\
\text { Population) } \\
\text { (Total No. 51) }\end{array}$ \\
\hline Positive & $12(57.1 \%)$ & $2(6.67 \%)$ & $3(5.9 \%)$ \\
\hline $\begin{array}{c}\text { Others (Negative } \\
\text { and Equivocal) }\end{array}$ & $9(42.9 \%)$ & $28(93.33 \%)$ & $48(94.1 \%)$ \\
\hline \multicolumn{2}{|c|}{ Table 1. HSV-2 IgM Positivity in all the 3 Groups } \\
\hline
\end{tabular}

HSV -2 IgG was positive in 27 out of the 51 STI patients (52.9\%). It was positive in 18 of the $21 \mathrm{HG}$ cases (85.7\%), including 15 cases of recurrent HG (71.42\%) and 3 cases of primary HG (14.3\%). One patient had equivocal value. HSV-2 IgG was positive in 9 out of 30 cases of other STIs (30\%) and 12 subjects out of the 51 in the comparison group (23.5\%). (Table-2).

\begin{tabular}{|c|c|c|c|}
\hline HSV-2 IgG & $\begin{array}{c}\text { Herpes } \\
\text { Genitalis } \\
\text { (Total No. } \\
\text { 21) }\end{array}$ & $\begin{array}{c}\text { Other } \\
\text { STIs } \\
\text { (Total } \\
\text { No. 30) }\end{array}$ & $\begin{array}{c}\text { Comparison } \\
\text { Group (General } \\
\text { Population) } \\
\text { (Total No. 51) }\end{array}$ \\
\hline Positive & $18(85.7 \%)$ & $9(30 \%)$ & $12(23.5 \%)$ \\
\hline $\begin{array}{c}\text { Others (Negative } \\
\text { and Equivocal) }\end{array}$ & $3(14.3 \%)$ & $21(70 \%)$ & $39(76.5 \%)$ \\
\hline \multicolumn{3}{|c|}{ Table 2. HSV-2 IgG Positivity in all the 3 Groups } \\
\hline
\end{tabular}

Thus, among 51 STI patients studied, any of the HSV antibody (either HSV-2 IgM or IgG) was positive in 30 patients (58.8\%), 20 out of the $21 \mathrm{HG}$ cases (95.2\%), 10 cases out of the 30 other STIs (33.3\%) and 14 subjects out of the 51 in the comparison group (27.5\%). (Table-3). 


\begin{tabular}{|c|c|c|c|}
\hline $\begin{array}{c}\text { Either of the HSV } \\
\text { Antibodies } \\
\text { (IgM or IgG) }\end{array}$ & $\begin{array}{c}\text { Herpes } \\
\text { Genitalis } \\
\text { (n=21) }\end{array}$ & $\begin{array}{c}\text { Other } \\
\text { STIs } \\
\text { (n=30) }\end{array}$ & $\begin{array}{c}\text { Comparison } \\
\text { Group (General } \\
\text { Population) } \\
\text { (n=51) }\end{array}$ \\
\hline Positive & $20(95.2 \%)$ & $10(33.3 \%)$ & $14(27.5 \%)$ \\
\hline $\begin{array}{c}\text { Others (Negative } \\
\text { and Equivocal) }\end{array}$ & $1(4.8 \%)$ & $20(66.7 \%)$ & $37(72.5 \%)$ \\
\hline \multicolumn{2}{|c|}{ Table 3. Any Antibody Positivity (Either IgM or IgG) } \\
\hline
\end{tabular}

Table 3. Any Antibody Positivity (Either IgM or IgG)

Positive Antibody test for both IgM and IgG was seen in 11 out of the 51 patients in the study group (21.6\%). Among the 21 cases of $\mathrm{HG}, 10$ cases $(47.6 \%)$ showed positivity for both IgM and IgG. $40 \%$ of the patients with first episode HG did not show IgM positivity and $50 \%$ of these patients showed IgG positivity. These patients had less severe clinical symptoms and less extensive lesions when compared to those with primary HG. Of the 30 cases of other STIs, 1 patient $(3.33 \%)$ had positivity for IgM and IgG. Among the 51 subjects of the comparison group, 1 (2\%) showed both IgM and IgG positivity. (Table-4).

\begin{tabular}{|c|c|c|c|}
\hline $\begin{array}{c}\text { Both IgM } \\
\text { and IgG } \\
\text { Positivity }\end{array}$ & $\begin{array}{c}\text { Herpes } \\
\text { Genitalis } \\
(\mathbf{n = 2 1 )}\end{array}$ & $\begin{array}{c}\text { Other } \\
\text { STIs } \\
\mathbf{( n = 3 0 )}\end{array}$ & $\begin{array}{c}\text { Comparison } \\
\text { Group (General } \\
\text { Population) } \\
\text { (n=51) }\end{array}$ \\
\hline Positive & $10(47.6 \%)$ & $1(3.33 \%)$ & $1(2 \%)$ \\
\hline $\begin{array}{c}\text { Others } \\
\text { (Negative, } \\
\text { Equivocal) }\end{array}$ & $11(52.4 \%)$ & $29(96.67 \%)$ & $50(98 \%)$ \\
\hline \multicolumn{2}{|c|}{ Table 4. Both HSV-2 IgM and IgG Positivity } \\
\hline
\end{tabular}

Comparison of HSV-2 IgM positivity of the 21 cases of HG with that of the 30 patients of other STIs showed that the test result in the former group was significantly very high $\left(\mathrm{X}^{2}\right.$ $=15.80, \mathrm{p}<0.001$ ). Comparison of HSV-2 IgG positivity of the 21 cases of HG with that of the 30 patients of other STIs also showed that the test result in in the former group was significantly high $\left(\mathrm{X}^{2}=15.39, \mathrm{p}<0.001\right)$. Similarly, comparison of HSV antibody titre for either IgM or IgG in HG cases with other STIs also showed significantly high values for HG case group $\left(X^{2}=19.54, p<0.001\right)$ and comparison of similar results of both IgM and IgG titre results showed significantly high values for the $\mathrm{HG}$ case group $\left(\mathrm{X}^{2}=14.32, \mathrm{p}<0.001\right)$. Comparison of the same values in $\mathrm{HG}$ cases with the comparison group (general population) also showed high values in $\mathrm{HG}$ cases (for IgM- $\mathrm{X}^{2}=23.7$, for IgG- $\mathrm{X}^{2}=23.67$, for either IgM or IgG- $\mathrm{X}^{2}=27.43$ and for both IgM and IgG- $\mathrm{X}^{2}$ $=23.96$ ), all with $p$ values $<0.001$. Comparison of the HSV antibody titres, for IgM, IgG, any one of IgM or IgG and both IgM and IgG of the other STI group and the Comparison group (general population showed no significant differences with $\mathrm{p}$ values greater than 0.05 .)

\section{DISCUSSION}

The ultimate aim of this study was to find out the prevalence of asymptomatic HSV-2 infection among patients with STIs other than herpes genitalis and a cross section of subjects from general population, who do not clinically have any evidence of STIs. Thus, 51 consecutive patients with STIs, out of which 21 were having HG and the remaining 30 having other STIs, and an equal number of 51 subjects from the general population were studied for HSV-2 IgM and IgG positivity.

HSV-2 IgM was positive in $60 \%$ of the cases of primary HG whereas HSV-2 IgG was positive in $93.6 \%$ cases of recurrent HG. Since the total HSV2 seropositivity among the 21 cases of HG was found to be $95.2 \%$, the chance of HSV1 causing HG appears to be less than $5 \%$. Recent reports have suggested that the prevalence of HG due to HSV1 is increasing to as high as $60-80 \%$ due to changes in socioeconomic conditions and changing sexual practices. ${ }^{3,4}$ The low IgM positivity of $60 \%$ in all cases of HG compared to the high IgG positivity of $93.6 \%$ may be due to the short duration of IgM persistence following infection or due to treatment with antiviral agents earlier in the course of disease as observed in previous studies. ${ }^{5,6}$

$40 \%$ of the patients with first episode genital herpes did not show IgM positivity among which $50 \%$ had IgG positivity and the other $50 \%$ had equivocal value for IgG. This reveals the fact that these patients did not develop the true primary infection, but presented with their first clinically evident lesions. This is in concordance with studies of Page et al. ${ }^{7}$ Also these patients without IgM positivity had less severe clinical symptoms and less extensive lesions when compared with those having primary HG. This is also in conformity with previous studies. 5,7

The observation of HSV-2 seropositivity in 58.8\% among the 51 cases of STIs studied, is in concordance with the data obtained from various STD clinics in India, where HSV2 seroprevalence among high risk group was $20 \%$ to $85 \% .8,9$ Also, the observation of HSV-2 seropositivity of $33.3 \%$ among the 'other STIs' is in concordance with a study by Van de Laar MJW. The higher HSV-2 seropositivity in patients with 'other STIs' $(33.3 \%)$ in comparison with that in general population $(27.5 \%)$ is also in concordance with the study conducted in Seattle. ${ }^{10}$ Thus, the higher rate of HSV-2 seroprevalence in patients with any of the STIs compared to the general population clearly indicates more chance of asymptomatic genital herpes infection in such patients than general population.

In this study, out of the total 102 individuals studied (21 patients with herpes genitalis, 30 patients with 'other STIs' and 51 persons from general population), 81 including all belonging to 'other STIs' and general population had never experienced any symptoms of herpes genitalis; 24 individuals of this group (10 patients from 'other STIs' and 14 from the general population) had serological positivity for HSV-2. Thus, $23.5 \%$ of the total 102 subjects must be taken as individuals with asymptomatic genital herpes infection.

\section{CONCLUSION}

In summary, the following are the important observations and conclusions made from this study of seroprevalence of HSV-2 antibodies among patients with herpes genitalis, 'other STIs' and a cross section of the general population-

1. The precipitating factors for triggering recurrence in $\mathrm{HG}$ patients were trauma during intercourse, physical strain and menstruation.

2. Extramarital contact was associated with transmission of herpes genitalis when compared with all other STIs.

3. Regional lymphadenopathy was more commonly found with recurrent $H G$ than primary indicating that lymphadenopathy occurs with increasing duration of the 
disease. Extragenital lesions were observed in male patients and thighs were the commonest site.

4. In general, HSV-2 antibody titres were positive in $95.2 \%$ of patients with herpes genitalis, HSV-2 IgM was positive in $60 \%$ patients and HSV-2 IgG in $93.6 \%$ patients with recurrent HG.

5. HSV-2 serology, either IgM or IgG, was positive in 30 cases $(58.8 \%)$. It was positive in 20 out of the 21 patients with HG (95.2\%), 10 cases out of the 30 patients with other STIs (33.33\%) and 14 of the comparison group of 51 subjects $(27.45 \%)$.

6. Positive Antibody test for both IgM and IgG was seen in 11 out of the 51 patients in the study group (21.6\%). Among the 21 cases of $\mathrm{HG}, 10$ cases (47.6\%) showed positivity for both IgM and IgG. $40 \%$ of the patients with first episode $\mathrm{HG}$ did not show IgM positivity and $50 \%$ of these patients showed IgG positivity, indicating that these patients were having Non-primary first episode than Primary HG. These patients had less severe clinical symptoms and less extensive lesions when compared with primary HG patients. Positivity for both IgM and IgG antibodies were less in patients with 'other STIs' and in the general population.

7. High titre of HSV-2 antibody showed a positive correlation with frequency of recurrences indicating the role of serology in assessing clinical activity in HG.

8. The HSV-2 seropositivity rates in patients with 'Other STIs' (33.3\%) and in the general population (27.5\%) who in fact are patients with asymptomatic genital herpes infection, strongly indicates the necessity for screening all STI patients and vulnerable individuals of the general population to serologically screen for genital herpes infection.

\section{REFERENCES}

[1] Thappa DM, Kumari R, Singh N. Viral STDs. In: Valia RG, Valia AR, (eds). IADVL text book of dermatology. $3^{\text {rd }}$ edn. Mumbai: Bhalani Publishing House 2008:1905-31.
[2] Corey L, Wald H. Genital herpes. In: Holmes KK, Mardh PA, Sparling PF, et al. (eds). Sexually transmitted diseases. $3^{\text {rd }}$ edn. New York: McGraw-Hill 1999:285312.

[3] Lowhagen G, Tunback P, Anderson K, et al. First episode of genital herpes in a Swedish STD population: a study of epidemiology and transmission by the use of herpes simplex virus (HSV) typing and specific serology. Sex Transm infect 2000;76(3):179-82.

[4] Corey L, Hansfield HH. Genital herpes and public health: addressing a global problem. JAMA 2000;283(6):791-4.

[5] de laar MJV, Termorshuizen F, Slomka MJ, et al. Prevalence and correlates of herpes simplex virus type 2 infection: evaluation of behavioural risk factors. Int J Epidemiol 1998;27(1):127-34.

[6] Ashley RL, Corey L. Effect of acyclovir treatment of primary genital herpes on the antibody response to herpes simplex virus. J Clin Invest 1984;73(3):681-8.

[7] Page J, Taylor J, Tideman R, et al. Is herpes simplex virus serology useful for the management of first episode genital herpes? Sex Transm Infect 2003;79(4):276-9.

[8] Shivaswamy KN, Thappa DM, Jaisankar TJ, et al. High seroprevalence of HSV-1 and HSV-2 in STD clinic attendees and non-high risk controls: a case control study at a referral hospital in south India. Ind J Dermatol Venereol Leprol 2005;71(1):26-30.

[9] Kumar B, Sahoo B, Gupta S, et al. Rising Incidence of Genital Herpes over Two Decades in a Sexually Transmitted Disease Clinic in North India. Int J STD AIDS 2002;29(2):74-8.

[10] Van de laar MJW, Termorshuizen F, Slomka MJ. Prevalence and correlates of herpes simplex virus type 2 infection: evaluation of behavioural risk factors. Int J Epidemiol. 1998;27:127-134.

[11] Malkin JE. Epidemiology of genital herpes simplex virus infection in developed countries. Herpes 2004;1:2A-23A. 